\title{
Hand and Handprint Measurements in the Estimation of Stature in a Sri Lankan Population
}

\author{
Mediciones de Manos y Huellas de Manos en la Estimación \\ de la Estatura en una Población de Sri Lanka \\ Deepthi Nanayakkara ${ }^{1}$; Lakshika S. Nawarathna²; Tharanga Nandasena ${ }^{1}$; \\ Sandeep Alahakoon ${ }^{1}$; Sajjiv Ariyasinghe ${ }^{1}$ \& Kapila Arambawatta ${ }^{1}$
}

NANAYAKKARA, D.; NAWARATHNA, L. S. ; NANDASENA, T.; ALAHAKOON, S.; ARIYASINGHE, S. \& ARAMBAWATTA,

K. Hand and handprint measurements in the estimation of stature in a Sri Lankan population Int. J. Morphol., 39(1):222-230, 2021.

SUMMARY: The present study was undertaken to generate sex-specific simple and multiple regression models for the estimation of stature using hand and handprint measurements in a Sri Lankan population. The sample comprises 51 males and 66 females in the age range of 20 to 26 years. The stature and eight measurements from each hand and its corresponding print of each subject were collected using standard anthropometric instruments and techniques. All hand and handprint measurements showed significantly positive correlation ( $\mathrm{p}$ value $<0.05$ ) with the stature in both sexes. Stature prediction accuracy for simple linear regression equations ranged from $\pm 4.41-5.92$ $\mathrm{cm}$ and $\pm 4.0-5.22 \mathrm{~cm}$ for the left and right hand measurements in males and females, respectively. The corresponding figures for the left and right handprint measurements were $\pm 4.57-5.95 \mathrm{~cm}$ and $\pm 4.36-5.52 \mathrm{~cm}$, respectively. The highest stature prediction accuracy was shown by the multiple regression models derived from hand measurements. The stature estimating formulae reported in this study using hand measurements have important application in the identification of unknown human remains, particularly when they are partial, mutilated or dismembered. Similarly, it is envisaged that formulae derived from the handprint measurements will be useful in crime scene investigations.

KEY WORDS: Forensic anthropology; Hand measurements; Handprints; Stature.

\section{INTRODUCTION}

Anthropometry, which signifies the technique of expressing the shape of the human body in numbers has been widely used in forensic identification. The most important step during the identification of unknown, decomposed corpses and human skeletal remains is the creation of a biological profile through the estimation of sex, age, ethnicity and stature. The estimation of stature is an important aspect that provides useful information towards narrowing the pool of potentially matching identities.

It is widely agreed that stature shows positive correlations with the dimensions of various skeletal components (Trotter \& Gleser, 1952; Byers et al. 1989; Meadows \& Jantz, 1992; Ryan \& Bidmos, 2007). The earliest formal tables for the estimation of stature were introduced by Rollet (1888) using all six long bones of the upper and lower limbs. Using Rollet's data on long bone lengths, Pearson (1898) developed regression equations for the prediction of stature. His revelations emphasized the fact that the application of regression formulae from one population to another must be made with great caution. Since then, numerous studies have been carried out in this direction, providing single and multiple regression equations using measurements of various skeletal and body fragments for the estimation of stature in different population groups (Pearson; Trotter \& Gleser; Byers et al.; Meadows \& Jantz; Celbis \& Agritmis, 2006; Ryan \& Bidmos; Nanayakkara et al., 2018).As skeletal development is strongly influenced by genetic and environmental factors (Plavcan, 2012), an equation derived from a certain population will not be applicable to another; this explains the necessity for establishing population and sex-specific stature estimation formulae. Moreover, the highest predictive accuracy of such formulae can be achieved only when they are applied to the same population from which they were derived. This justifies the collection of data from more population groups to make a comprehensive database.

\footnotetext{
${ }^{1}$ Department of Basic Sciences, Faculty of Dental Sciences, University of Peradeniya, 20400 Peradeniya, Sri Lanka.

${ }^{2}$ Department of Statistics and Computer Science, Faculty of Science, University of Peradeniya, 20400 Peradeniya, Sri Lanka.
} 
The reliable and accurate methods available for stature estimation require the preservation of long bones. It is widely accepted that regression formulae derived using the dimensions of intact long bones of the upper and lower limbs, especially the femur, provide more accurate estimates of stature (Bidmos, 2008). With the rising incidence of mass disasters there is an increased likelihood of dismembered peripheral parts of the body such as the hand and foot being presented to forensic experts for analysis. In these circumstances the stature estimating formulae established using a complete skeleton or the intact long bones are inapt for the analysis.

Numerous studies have described anthropometric approaches to estimating stature from different body fragments (Krishan \& Sharma, 2007; Ishak et al. 2012; Zulkifly et al., 2018). Further, these studies have demonstrated that anthropometry of the hand shows considerable potential and accuracy in the estimation of stature; the accuracies closely reaching the standards established for long bones (Ishak et al.; Zulkifly et al.). Partial or complete handprints discovered in crime scenes have also been shown to provide valuable clues in the identification of a criminal (Ishak et al.; Zulkifly et al.). The forensic utility of anthropometric approaches of the hand and handprints for estimating stature has been widely studied (Krishan \& Sharma; Ishak et al.; Ozaslan et al., 2012; Laulathaphol et al., 2013; Zulkifly et al.).

Despite the need for such studies, derivation of stature estimation formulae using hand and handprint dimensions has scarcely been discussed for the Sri Lankan population.Therefore, the present study was undertaken to ascertain the correlation between the stature and hand and handprint measurements, and to generate population specific regression models to estimate stature of unidentified males and females in a Sri Lankan population.

\section{MATERIAL AND METHOD}

The present study was conducted in the Department of Basic Sciences, Faculty of Dental Sciences, University of Peradeniya, Sri Lanka. Participation in the study was entirely on a voluntary basis and participating subjects were provided with an information sheet elucidating the purpose of the study. The informed consent was obtained from the volunteering subjects prior to acquisition of measurements. In addition, basic demographic data (i.e. sex, age and ethnicity) were also collected by administering a questionnaire. The individuals who were apparently healthy and having no physical deformities were recruited. Further, only the participants belonging to the major ethnic group in Sri Lanka, Sinhalese, were included in the present analysis as the number available for other ethnic groups was inadequate for statistical analysis. A total of 117 young and healthy undergraduate students, comprising of 51 males and 66 females, within the age range of 20 to 28 years were included in the present study. The study protocol, including the consent procedure was reviewed and approved by the Ethics Review Committee of Faculty of Dental Sciences, University of Peradeniya, Sri Lanka (Research Project No. ERC/ FDS/ UOP/1/2018/37).

Measurement of stature. The living height or stature of each subject was measured using a stadiometer (TTM stadiometer; Tsutsumi Co. Ltd., Tokyo, Japan) adopting the protocol described in a previous study (Ishak et al.).

Anthropometric measurements of hand. Using a digital vernier caliper (Mitutoyo, Japan) and a measuring tape when necessary, eight anthropometric measurements were taken on both right and left hands of each individual adopting the landmark definitions described in previous studies (Krishan \& Sharma; Ishak et al., 2012; Ozaslan et al.; Laulathaphol et al.; Zulkifly et al.). A description of all measurements used in this study are presented in Table I and illustrated in Figure 1.

Handprint measurements. Right and left handprints of all participants were obtained using an inkpad, with a nonreactive, and non-indelible ink. The hands of the participant were gently pressed against the ink pad and then placed with a little pressure on A4 sized white paper to make an outline of handprints. The paper was allowed to dry after which a total of eight measurements were obtained as described in previous studies (Ishak et al.; Zulkifly et al.) (Table I; Fig. 1).

Statistical analyses. Tests for reproducibility of measurements were conducted prior to data acquisition of the study using Lin's concordance correlation coefficient of reproducibility (CCC) (Lin, 1989). For this purpose stature and hand measurements were repeated in a $10 \%$ of the sample with a minimum of $24-\mathrm{h}$ interval between re-measurement. The measurement technique was considered as reliable as the CCC values for allmeasurements were found to be within the accepted range (0.900 and 1). A specific measurement was recorded by a single investigator (one specific investigator each for measuring stature, hands and handprints); this eliminated the inter-observer error. Statistical analyses were performed using the Statistical Package for the Social Sciences (SPSS), version 21. 

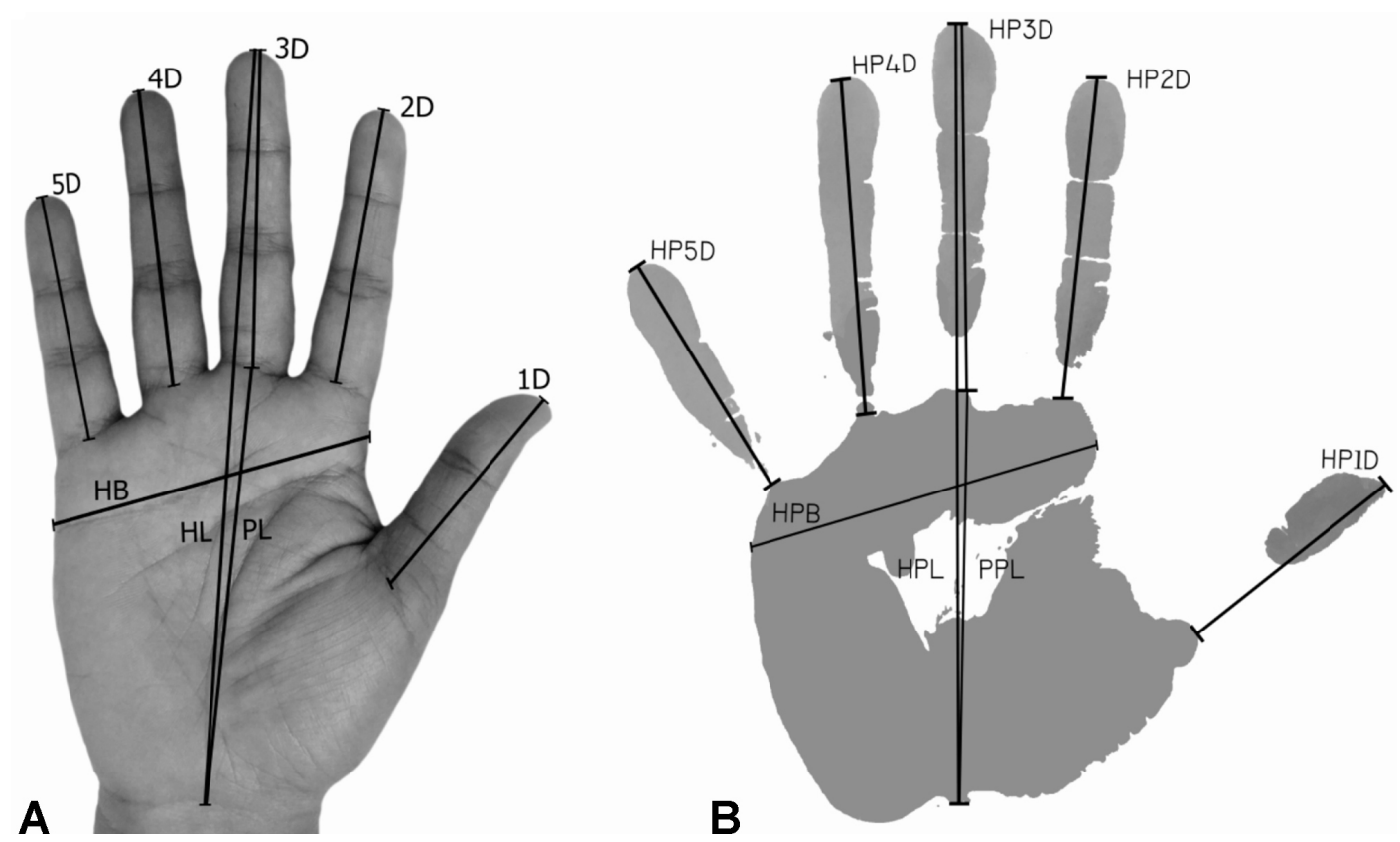

Fig. 1. A.Hand measurements: hand length (HL); hand breadth (HB); palm length (PL); 1st digit length (1D); 2nd digit length (2D); 3rd digit length (3D); 4th digit length (4D) and 5th digit length (5D). B. Handprint measurements: handprint length (HPL); handprint breadth (HPB); palm print length (PPL); handprint 1st digit length (HP1D); handprint 2nd digit length (HP2D); handprint 3rd digit length (HP 3D); handprint 4th digit length (HP4D) and handprint 5th digit length (HP5D).

Table I. Description of hand and handprint measurements used in the present study.

\begin{tabular}{|c|c|}
\hline Measurement and abbreviation & escription \\
\hline Hand length(HL) & $\begin{array}{l}\text { he distance between the mid-point of the distal transverse crease of the wrist } \\
o \text { the most anterior projection of the tip of the middle finger }\end{array}$ \\
\hline Hand breadth (HB) & $\begin{array}{l}\text { the distance between the most lateral point on the head of the } 2^{\text {nd }} \text { metacarpal to } \\
\text { the most medial point on the head of the } 5^{\text {th }} \text { metacarpal bone }\end{array}$ \\
\hline Palm length (PL) & $\begin{array}{l}\text { the distance from the mid-point of the distal transverse crease of the wrist to } \\
\text { the proximal flexion crease of the middle finger }\end{array}$ \\
\hline $\begin{array}{l}\text { Digit lengths: Thumb (1D); Index (2D); } \\
\text { Middle (3D); Ring (4D); Little (5D) finger } \\
\text { length }\end{array}$ & $\begin{array}{l}\text { the distance between the proximal flexion crease of the finger to the tip of the } \\
\text { respective finger }\end{array}$ \\
\hline Handprint breadth (HPB) & $\begin{array}{l}\text { the distance from the most laterally projected part of the palm print at the } 2^{\text {nd }} \\
\text { metacarpal to the most medially projected part of the palm print atthe distal } \\
\text { transverse crease }\end{array}$ \\
\hline Handprint length (HPL) & $\begin{array}{l}\text { the distance from the baseline of the print (transverse line from the most } \\
\text { inferior point of the medial border of the palm) to the tip of the middle finger }\end{array}$ \\
\hline Palm print length (PPL) & $\begin{array}{l}\text { the distance from the baseline of the print to the proximal flexion crease of the } \\
\text { middle finger }\end{array}$ \\
\hline $\begin{array}{l}\text { Handprint digit lengths: Thumb (HP1D); } \\
\text { Index (HP2D); Middle (HP3D); Ring } \\
\text { (HP4D); Little (HP5D) finger length }\end{array}$ & $\begin{array}{l}\text { the distance between the proximal flexion creases of the finger to the tips } \\
\text { (dactylion) of the respective fingers }\end{array}$ \\
\hline
\end{tabular}

\section{RESULTS}

Descriptive statistics of stature, hand and handprint measurements. Kolmogorov-Smirnov test and q-q plots carried out showed normality of data. Descriptive statistics including the mean, standard deviation, minimum and maximum values for each of the hand and handprint for measurements of both left and right sides of both sexes are illustrated in Table II. All the measurements were found to be significantly larger in males than in females ( $p<0.001)$. 
In the present study, the mean measured stature of males was $170.33 \pm 6.11 \mathrm{~cm}$ (range 158.4-189.0) whereas in females a mean stature of $157.38 \pm 5.82 \mathrm{~cm}$ (range 145.0 171.4) was observed.

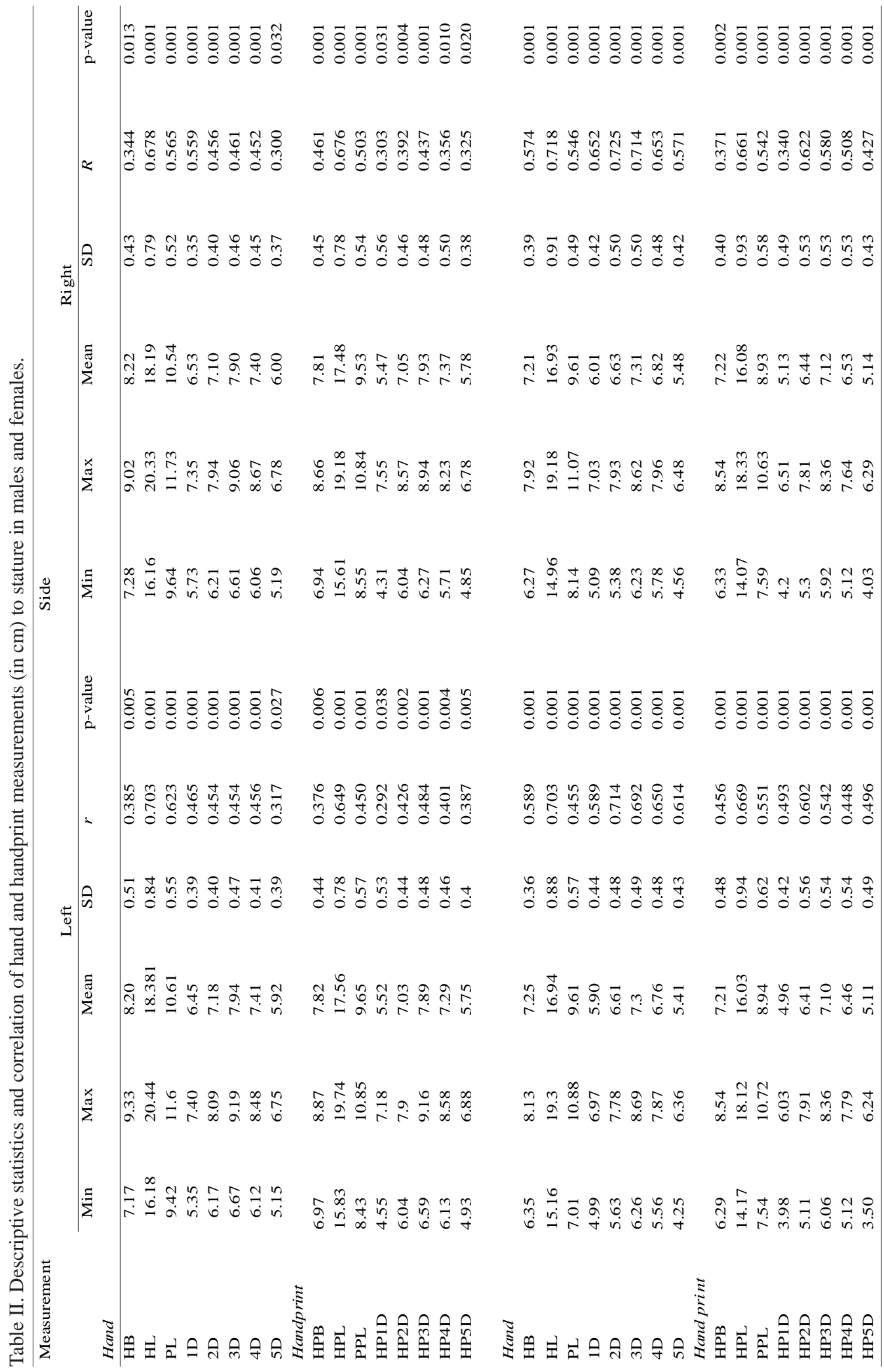

Bilateral variation in the hand and h a n d p r i n t dimensions. The results of the twosample t- test carried out to analyze the bilateral variation in the hand and handprint dimensions showed significant differences $(p<0.05)$ in the measurements of HL, PL, 1D, 2D and 5D between the left and right hands among the males. Significant differences $(\mathrm{p}<0.05)$ were also observed among the females in the measurements of $\mathrm{HB}, 1 \mathrm{D}, 4 \mathrm{D}$ and 5D between the left and right hands. While the PPL differed significantly $(\mathrm{p}<$ 0.05 ) between the left and right palmprints of the males, the females $\mathrm{d}$ e m o n s t r a te d significant differences $(p<0.05)$ in the HP1D and HP4D of left and right handprints.

Correlation between stature and hand and h a n d p r i n t measurements. The c or r e lation coefficients between stature and all hand and handprint measurements are also shown in Table II. All hand and handprint measurements of both left and right side showed significantly positive correlation to 


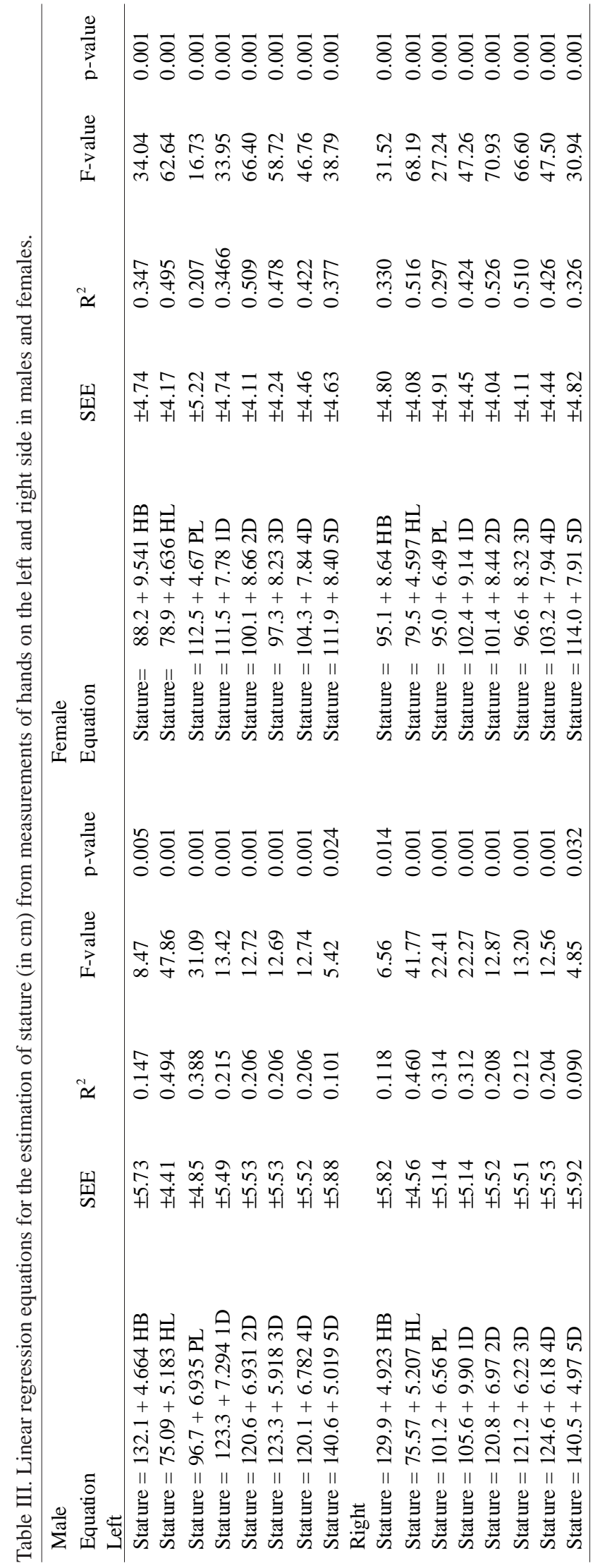

stature (p-value < 0.05). In males the hand measurements which exhibited the strongest correlation with stature was the HL ( $r=0.703,0.678)$ while the lowest was shown by $5 \mathrm{D}(\mathrm{r}=0.317,0.300)$. Similarly, in females the strongest correlation coefficient was shown by $2 \mathrm{D}$ length $(\mathrm{r}=0.714$, $0.725)$ followed by the HL $(r=0.703,0.718)$ while the PL showed the lowest $(r=0.455,0.546)$ correlation with stature. With reference to handprint measurements, in both males and females, the strongest correlation was exhibited by the HPL (males $-r=0.649-0.676$, females $-r=.661-.669$ ); this correlation was seen in both left and right handprints.

Simple linear regression. The simple linear regression equations computed to estimate stature using each measurement of the hand and handprints separately for sex and side are presented in Tables III and IV. The standard error of estimate (SEE) predicts the deviation of estimated stature from the actual stature. A low SEE value indicates greater reliability in the estimated stature. In the present study, the SEE of simple linear regression equations ranged from \pm 4.41 to $\pm 5.88 \mathrm{~cm}$ and \pm 4.04 to $\pm 5.22 \mathrm{~cm}$ for left and right hand measurements in males and females, respectively. The corresponding figures for left and right handprint measurements were $\pm 4.57 \mathrm{~cm}$ to $\pm 5.95 \mathrm{~cm}$ and \pm 4.36 to $\pm 5.52 \mathrm{~cm}$, respectively.

The range of SEE observed for measurements of the left and right hands of females was lower (left hand: \pm 4.11 to $\pm 5.22 \mathrm{~cm}$; right hand: \pm 4.04 to $\pm 4.91 \mathrm{~cm}$ ) than the range observed for males (left hand: \pm 4.41 to \pm 5.88 ; right hand: \pm 4.56 to \pm 5.92 ) (Table III). Further, the females demonstrated lower ranges of SEE for measurements of left and right handprints (left: \pm 4.36 to $\pm 5.24 \mathrm{~cm}$; right: \pm 4.40 to $\pm 5.45 \mathrm{~cm}$ ) than those of males (left: \pm 4.72 to \pm .95 $\mathrm{cm}$; right: \pm .57 to $\pm 5.90 \mathrm{~cm}$ ) (Table IV).

Multiple regression. Sex-specific bilateral multiple regression equations for the estimation of stature based on various combinations of variables separately for hand and handprint measurements are presented in Tables 5 and 6 , respectively. Only the most accurate models using stepwise analysis are presented. Besides, in addition to R-squared values, adjusted R-squared values were calculated to compare the explanatory power of regression models that contain different numbers of predictors. Multiple regression equations resulted in lower SEE values and higher Rsquared values than do linear regression equations. With regard to the multiple regression models generated using hand measurements, the least SEE observed in males is \pm $3.95 \mathrm{~cm}$ whereas in females it is $\pm 3.82 \mathrm{~cm}$ (Table V); for the handprint measurements the least SEE observed in males is $\pm 4.62 \mathrm{~cm}$ and in females it is $\pm 4.32 \mathrm{~cm}$ (Table $\mathrm{VI})$. 

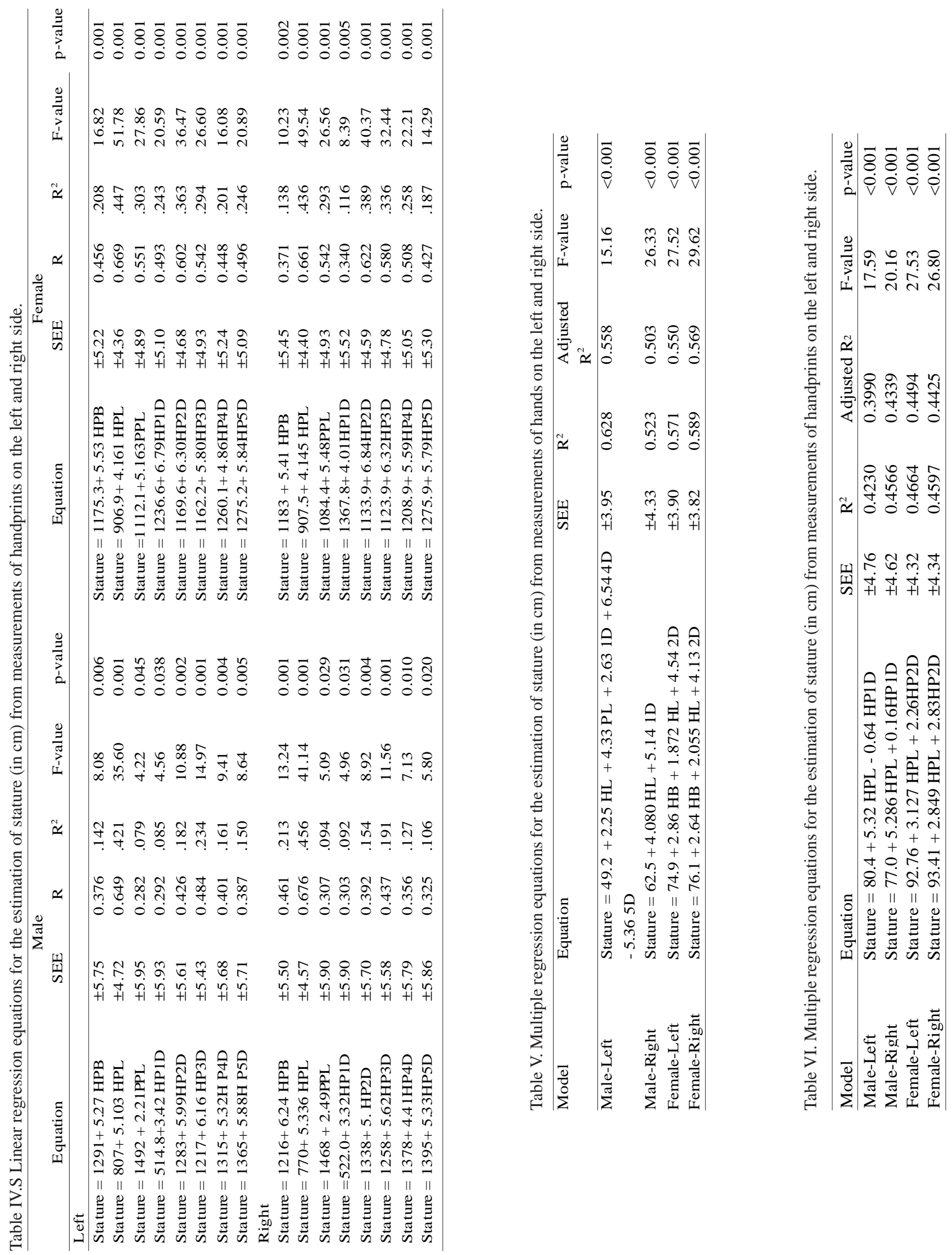


\section{DISCUSSION}

The estimation of stature of unknown human remains becomes a challenging task when the remains are partial, mutilated or dismembered as in mass disasters. In such situations important parameters such as long bones which are commonly used for stature estimation may not be available. A practical alternative is to develop new formulae of stature estimation using body appendages that are likely to survive and be recovered.

In concurrence with other similar studies (Krishan \& Sharma; Ishak et al.; Ozaslan et al.; Laulathaphol et al.; Zulkifly et al.) the males in the present study exhibited significantly higher stature as well as hand and handprint measurements when compared with those of the females. These differences between the sexes are attributable to the influence of genetic and environmental factors on the growth and development of the skeletal system (Frayer \& Wolpoff, 1985). Hormonal influence, which causes early maturity and cessation of bone growth in the females gives the males an additional two or more years of bony growth than in the females (Krishan \& Sharma). The aforementioned findings highlight the importance of elaborating sex-specific standards to accurately estimate stature. Hence, the purpose of this study was to formulate new sex-specific stature estimating models using hand and handprint measurements applicable to the Sinhalese, the major ethnic group in Sri Lanka.

Furthermore, previous population studies have reported the existence of bilateral asymmetry in hand dimensions (Krishan \& Sharma; Ishak et al.; Ozaslan et al.; Laulathaphol et al.; Zulkifly et al.). Consistent with the findings reported in previous studies, the results of the present study indicated that several hand and handprint measurements showed statistically significant bilateral asymmetry in both males and females. The observed bilateral asymmetry in hand and handprint measurements may partially be attributed to the handedness of the subject as postulated by previous researchers (Rastogi et al., 2008). Conversely, a study by Nandi et al. (2018) in an adult Nigerian population found no significant bilateral asymmetry in hand and handprint measurements of both males and females.

The present results showed that the stature of an individual was significantly and positively correlated with all hand and handprint measurements. Among the hand measurements, the HL $(r=0.703,0.678)$ exhibited the strongest correlation with stature in males whereas in females the 2D length $(r=0.714,0.725)$ followed by the
HL $(r=0.703,0.718)$ showed the strongest correlations for both left and right sides. Previous studies in North Indian (Krishan \& Sharma), South Indian (Rastogi et al.), Western Australian (Ishak et al.) and Thai (Laulathaphol et al.) populations have revealed the hand length as the measurement showing the strongest correlation with stature. In accordance with the findings reported in previous studies (Ishak et al.), with reference to the handprint measurements, in both males and females, the strongest correlation was shown by the HPL (males $-r=0.649-0.676$, females $-r=$ 0.661-0.669) in both left and right handprints.

The presence of a positive linearity between the stature and hand and handprint measurements facilitated the formulation of regression equations which can be successfully utilized for stature estimation in the Sri Lankan population. In assessing the accuracy and reliability of the simple linear regression equations, the standard error of estimate (SEE) which predicts the deviation of estimated stature from the actual stature was employed. A low value of SEE indicates a greater reliability in the estimated stature.

In the present study, the SEE of the simple linear regression equations ranged from \pm 4.41 to $\pm 5.92 \mathrm{~cm}$ and \pm 4.04 to $\pm 5.22 \mathrm{~cm}$ for the left and right hand measurements in males and females, respectively. The range of SEE recorded in the present study is lower than those reported previously for other population groups; Uhrová et al. (2015) for Slovak adults $( \pm 5.01$ to \pm 6.11$)$; Ozalan et al. (2012) for Turks ( \pm 5.46 to \pm 6.77 ); Ishak et al. for Western Australians ( \pm 4.74 to \pm 6.40 ); Rastogi et al. for North Indians ( \pm 4.11 to \pm 5.97$)$. The higher SEE values calculated for the regression models by these authors may possibly be related to the wide diversity in these measurements in their study populations. On the other hand, studies concerning the Thai populations (Laulathaphol et al.) $( \pm 3.29 \mathrm{~cm}$ to $\pm 4.878 \mathrm{~cm})$ and West Bengal (Pal et al., 2016) ( \pm 3.49 to $\pm 4.28 \mathrm{~cm}$ ) demonstrated lower SEE values for the regression models derived from hand measurements.

In evaluating the simple linear regression models formulated for hand measurements, the values of SEE were lowest for the HL of left and right hands ( \pm 4.41 to - \pm 4.56 ) in males whereas in females the lowest SEE values were exhibited by the $2 \mathrm{D}$ lengths ( \pm 4.11 to \pm 4.04 ). The SEE values of the $\mathrm{HL}$ of left and right hands of females $( \pm 4.17$ to \pm 4.08 ) were marginally higher than those of $2 \mathrm{D}$ length values. Previous research has demonstrated the $\mathrm{HL}$ as the most accurate hand measurements in predicting the stature. The range of SEE has been reported as \pm 4.74 to $\pm 5.17 \mathrm{~cm}$, \pm 5.46 to $\pm 6.03 \mathrm{~cm}, \pm 4.36$ to $\pm 7.50 \mathrm{~cm}, \pm 3.78$ to $\pm 5.22 \mathrm{~cm}$ in Western Australian (Ishak et al.), Turkish (Ozalan et al. 
2012), Malaysian (Zulkifly et al.) and North Indian (Rastogi et al.) populations, respectively. According to previous research (Ishak et al.; Zulkifly et al.), the most accurate handprint regression models for both males and females were shown by the HPL (SEE $\pm 4.36, \pm 4.72 \mathrm{~cm}$ ). In a Western Australian (Ishak et al.) and Malaysian (Zulkifly et al.) population the most accurate regression models generated using the HPL recorded ranges of SEE as \pm 5.42 to \pm 5.48 and \pm 4.67 to \pm 7.55 , respectively.

Interestingly, the findings of this study further revealed that the SEE values exhibited by females for the measurements of hand $( \pm 4.04$ to $\pm 5.22 \mathrm{~cm})$ and handprints $( \pm 4.36$ to $\pm 5.52 \mathrm{~cm})$ were lower than those of males (hand: \pm 4.41 to $\pm 5.92 \mathrm{~cm}$; handprint: \pm 4.57 to $\pm 5.95 \mathrm{~cm}$ ), implying that stature can be estimated with greater precision in females than in males utilizing these regression models.

Substantiating the views of previous researchers (Krishan \& Sharma; Ishak et al.; Zulkifly et al.) the multiple regression equations derived for both males and females resulted in superior prediction accuracy than the equations obtained from single variables, presenting lower SEE values and higher $\mathrm{R}$-squared values. In view of hand measurements, the least SEE in males is $\pm 3.95 \mathrm{~cm}$ whereas in females it is $\pm 3.82 \mathrm{~cm}$. In males, the multiple regression equation utilizing HL,PL, 1D, 4D and 5D presented the greatest accuracy in estimating stature $(\mathrm{SEE}= \pm 3.95, \mathrm{R} 2=$ 0.6275). On the other hand, in females, the multiple regression equation using $\mathrm{HB}, \mathrm{HL}$ and $2 \mathrm{D}$ length (SEE $= \pm$ $3.82, \mathrm{R} 2=0.5890$ ) was more accurate than the simple regression equation using the $2 \mathrm{D}$ or the HL. Conversely, with regard to the multiple regression models formulated for handprint measurement, none demonstrated superior accuracy than the simple linear regression equations derived from HPL in both males and females.

The results of the present study clearly demonstrate that the predictive accuracy of stature estimation varies with each different population. This again emphasizes the significance of generating population-specific standards to accurately estimate stature. Moreover, the results indicate that hand and handprint measurements provide accurate and reliable means of stature estimation and will therefore be useful in assisting forensic anthropologists in profiling remains in crime scenes and victim identification in mass fatalities.

The present study is limited by its relatively small sample size. Further studies involving large samples of different ethnic groups in Sri Lanka are desired. Nonetheless, these preliminary results provide the baseline data for more detailed studies in the future.
NANAYAKKARA, D.; NAWARATHNA, L. S. ; NANDASENA, T.; ALAHAKOON, S.; ARIYASINGHE, S. \& ARAMBAWATTA, K. Mediciones de manos y huellas de manos en la estimación de la estatura en una población de Sri Lanka. Int. J. Morphol., 39(1):222-230, 2021.

RESUMEN: El estudio se llevó a cabo para generar modelos de regresión simple y múltiple de acuerdo al sexo, para la estimación de la estatura utilizando medidas de manos y huellas de manos en una población de Sri Lanka. La muestra comprendió 51 hombres y 66 mujeres entre 20 a 26 años de edad. Se analizaron la estatura y ocho medidas de cada mano y su impresión correspondiente de cada sujeto utilizando instrumentos y técnicas antropométricas estándar. Todas las mediciones de manos y las huellas de manos indicaron una correlación significativamente positiva (valor de $\mathrm{p}<0.05$ ) con la estatura en ambos sexos. La precisión de la predicción de la estatura para las ecuaciones de regresión lineal simple varió de $\pm 4,41$ a $5,92 \mathrm{~cm}$ y $\pm 4,0$ a $5,22 \mathrm{~cm}$ en las medidas de la mano izquierda y derecha en hombres y mujeres, respectivamente. Las cifras correspondientes para las medidas de la huella de la mano izquierda y derecha fueron $\pm 4,57-5,95 \mathrm{~cm}$ y \pm 4,36-5,52 cm, respectivamente. La precisión de predicción de la estatura más alta se mostró mediante los modelos de regresión múltiple derivados de las mediciones manuales. Las fórmulas de estimación de la estatura reportadas en este estudio utilizando medidas manuales tienen una aplicación importante en la identificación de restos humanos desconocidos, particularmente cuando son parciales, o se encuentran mutilados o desmembrados. Además, se prevé que las fórmulas derivadas de las mediciones de huellas de manos serán útiles en las investigaciones criminales.

PALABRAS CLAVE: Antropología forense; Medidas de las manos; Huellas de las manos; Estatura.

\section{REFERENCES}

Bidmos, M. A. Stature reconstruction using fragmentary femora in South Africans of European descent. J. Forensic Sci., 53(5):1044-8, 2008.

Byers, S.; Akoshima, K. \& Curran, B. Determination of adult stature from metatarsal length. Am. J. Phys. Anthropol., 79(3):275-9, 1989.

Celbis, O. \& Agritmis, H. Estimation of stature and determination of sex from radial and ulnar bone lengths in a Turkish corpse sample. Forensic Sci. Int., 158(2-3):135-9, 2006.

Frayer, D. W. \& Wolpoff, M. H. Sexual dimorphism. Annu. Rev. Anthropol., 14:429-73, 1985.

Ishak, N. I.; Hemy, N. \& Franklin, D. Estimation of stature from hand and handprint dimensions in a Western Australian population. Forensic Sci. Int., 216(1-3):199.e1-7, 2012.

Krishan, K. \& Sharma, A. Estimation of stature from dimensions of hands and feet in a North Indian population. J. Forensic Leg. Med., 14(6):327-32, 2007.

Laulathaphol, P.; Tiensuwarr, M. \& Riengrojpitak, S. Estimation of stature from hand measurements in Thais. SDU Res. J., 6(1):37-47, 2013.

Lin, L. I. A concordance correlation coefficient to evaluate reproducibility. Biometrics, 45(1):255-68, 1989.

Meadows, L. \& Jantz, R. L. Estimation of stature from metacarpal lengths. J. Forensic Sci., 37(1):147-54, 1992.

Nanayakkara, D.; Vadysinghe, A. \& Nawarathna, L. S. Prediction of the length of the femur from its fragments in a Sri Lankan population. Aust. J. Forensic Sci., 52(3):303-12, 2018. 
Nandi, M. E.; Ibeabuchi, N. M.; Olabiyi, O. A.; Okubike, E. A. \& Iheaza, E. C. Stature reconstruction from handprint dimensions in an adult Nigerian student population. Forensic Sci. Addict. Res., 2(5):1-9, 2018.

Ozaslan, A.; Karadayi, B.; Kolusayin, M. O.; Kaya, A. \& Afsin, H. Predictive role of hand and foot dimensions in stature estimation. Rom. J. Leg. Med., 20:41-6, 2012.

Pal, A.; De, S.; Sengupta, P.; Maity, P. \& Dhara, P. C. Estimation of stature from hand dimensions in Bengalee population, West Bengal, India. Egypt. J. Forensic Sci., 6(2):90-8, 2016.

Pearson, K. Mathematical contributions to the theory of evolution. V. On the reconstruction of the stature of prehistoric races. Proc. R. Soc. Lond., 63:389-400, 1898.

Plavcan, J. M. Body size, size variation, and sexual size dimorphism in early homo. Curr. Anthropol., 53(S6):S409-S423, 2012.

Rastogi, P.; Nagesh, K. R. \& Yoganarasimha, K. Estimation of stature from hand dimensions of north and south Indians. Leg. Med., 10(4):185-9, 2008.

Rollet, E. De la Mensuration des Os Longs des Membres dans ses Rapports avec L'Anthropologie, la Clinique et la Médecine Judiciaire. Thesis. Lyon, Faculté de Médecine et de Pharmacie de Lyon, 1888. Available from: https://gallica.bnf.fr/ark:/12148/bpt6k97653475.texteImage\#

Ryan, I. \& Bidmos, M. A. Skeletal height reconstruction from measurements of the skull in indigenous South Africans. Forensic Sci. Int., 167(1):1621, 2007.

Trotter, M. \& Gleser, G. C. Estimation of stature from long bones of American Whites and Negroes. Am. J. Phys. Anthropol., 10(4):463514, 1952.

Uhrová, P.; Ben`uš, R.; Masnicová, S.; Obertová, Z.; Kramárová, D.; Kyselicová, K.; Dörnhöferová, M.; Bodoriková, S. \& Nes`čáková, E. Estimation of stature using hand and foot dimensions in Slovak adults. Leg. Med. (Tokyo), 17(2):92-7, 2015.

Zulkifly, N. R.; Abd Wahab, R.; Layang, E.; Ismail, D.; Desa, W. N. S. M.; Hishamd, S. \& Mahat, N. A. Estimation of stature from hand and handprint measurements in Iban population in Sarawak, Malaysia and its applications in forensic investigation. J. Forensic Leg. Med., 53:3545, 2018.
Corresponding author:

Professor Deepthi Nanayakkara, BDS, PhD

Division of Anatomy, Department of Basic Sciences

Faculty of Dental Sciences

University of Peradeniya

SRI LANKA

Email :deepthinanayakkara@yahoo.com

Received: 20-09-2020

Accepted: 10-11-2020

ORCID

Deepthi Nanayakkara

http://orcid.org/0000-0002-5585-8114

Lakshika S.Nawarathna

Ikhttp://orcid.org/0000-0001-9665-5471

Tharanga Nandasena

http://orcid.org/0000-0002-7712-8761

Sajjiv Ariyasinghe

http://orcid.org/0000-0002-8359-4961

Sandeep Alahakoon

http://orcid.org/0000-0002-0817-9944

Kapila Arambawatta

http://orcid.org/0000-0002-8152-6228 